\title{
Detection of Bordetella pertussis from Clinical Samples by Culture and End-Point PCR in Malaysian Patients
}

\author{
Tan Xue Ting, Rohaidah Hashim, Norazah Ahmad, and Khairul Hafizi Abdullah \\ Bacteriology Unit, Infectious Disease Research Centre, Institute for Medical Research, Jalan Pahang, 50588 Kuala Lumpur, Malaysia \\ Correspondence should be addressed to Tan Xue Ting; tanxt@imr.gov.my
}

Received 29 January 2013; Revised 26 March 2013; Accepted 28 March 2013

Academic Editor: Sam R. Telford

Copyright (C) 2013 Tan Xue Ting et al. This is an open access article distributed under the Creative Commons Attribution License, which permits unrestricted use, distribution, and reproduction in any medium, provided the original work is properly cited.

\begin{abstract}
Pertussis or whooping cough is a highly infectious respiratory disease caused by Bordetella pertussis. In vaccinating countries, infants, adolescents, and adults are relevant patients groups. A total of 707 clinical specimens were received from major hospitals in Malaysia in year 2011. These specimens were cultured on Regan-Lowe charcoal agar and subjected to end-point PCR, which amplified the repetitive insertion sequence IS481 and pertussis toxin promoter gene. Out of these specimens, 275 were positive: 4 by culture only, 6 by both end-point PCR and culture, and 265 by end-point PCR only. The majority of the positive cases were from $\leq 3$ months old patients $(77.1 \%)(P<0.001)$. There was no significant association between type of samples collected and end-point PCR results $(P>0.05)$. Our study showed that the end-point PCR technique was able to pick up more positive cases compared to culture method.
\end{abstract}

\section{Introduction}

Whooping cough is a major cause of the infant [1] and childhood mortality [2]. World Health Organization (WHO) reported about 16 million pertussis cases worldwide in 2008, in which $95 \%$ of cases occurred in developing countries and more than 100000 children died from this disease [1]. Pertussis still remains endemic despite the introduction of vaccination program in 1974 [3]. During 2003-2007, there were 43482 cases or an incidence of 4.1 per 100000 people reported from 20 European countries [4]. In the United States, the incidence of pertussis also increased from 3.53 in year 2007 to 5.54 in year 2009 [5]. Although pertussis is always classified as infants and children disease, an increasing number of cases in adolescents and adults group were also observed $[2,5]$.

According to the vaccination schedule of Malaysia, every citizen should be given vaccination at 2, 3, and 5 months old and a booster at 18 months old [6]. This is in line with the vaccination schedule recommended by WHO. Although there are two types of vaccines available, whole cell or acellular vaccine [6], the whole cell pertussis vaccine is the most widely used vaccine against pertussis [7]. The immunization coverage of three-dose pertussis vaccination is $95.3 \%$ [8].
Pertussis is a notifiable disease in Malaysia [9]. The incidence of pertussis has been less than 1 per 100000 people from 1989 to 2010 [10].

The clinical pertussis is defined by cough illness which last 2 weeks or more, with at least one of the symptoms of paroxysms of coughing, characteristic inspiratory whoop, and posttussive vomiting without apparent cause [11]. However, pertussis in adults and adolescents are rarely recognized because they normally have atypical course [12] or asymptomatic [13]. Hence, they become the reservoir of the disease and may transmit the infection to infants $[2,12]$. Pertussis may also result in many complications such as pneumonia, apnoea, encephalopathy, death, loss of weight, convulsion, loss of bladder control, and rib fractures [14].

Culture was the gold standard for the diagnosis of pertussis due to its specificity; however, it is slow and not sensitive [15]. Detection by real-time polymerase chain reaction has been carried out by many laboratories and was found to be useful in the diagnosis of $B$. pertussis infection [1618]. However, this method of detection requires the use of expensive instrument. Therefore, we applied end-point PCR technique and compared it with culture method to detect $B$. pertussis from suspected clinical samples. 


\section{Materials and Methods}

A total of 707 specimens were received from 57 Malaysian hospitals in year 2011. These samples were obtained from suspected pertussis cases as diagnosed by clinicians and sent to our laboratory for $B$. pertussis culture and end-point PCR detection. One sample was obtained per patient. The samples received were nasopharyngeal aspirates, nasopharyngeal swabs, tracheal aspirates, throat swabs, pernasal swabs, and endotracheal tube swabs. The nasopharyngeal aspirates were transported in sterile containers. The swab samples were transported in Regan-Lowe medium, Amies, Stuart, or without any transport medium. The samples were processed on the same day of arrival.

2.1. Culture. All swab samples were rolled onto separate Regan-Lowe charcoal agar. Regan-Lowe charcoal agar plates were prepared from dehydrated powder obtained from Oxoid and $23 \mu \mathrm{g} \mathrm{mL}^{-1}$ cephalexin, and $15 \% \mathrm{v} / \mathrm{v}$ defibrinated horse blood were added to the medium. For nasopharyngeal and tracheal aspirates, approximately $0.1 \mathrm{~mL}$ of the fluid was inoculated onto the Regan-Lowe charcoal agar plates. The agar plates were then incubated at $37^{\circ} \mathrm{C}$ aerobically. The plates were inspected after 72 hours. If no growth was observed, the plates were further reincubated until 120 hours. Any suspected colony was identified using B. pertussis-specific antisera (Difco, Sparks, MD, USA) [19].

2.2. Polymerase Chain Reaction. The same swab samples were transferred into $1.5 \mathrm{~mL}$ Eppendorf tubes containing phosphate buffered saline (PBS) ( $\mathrm{pH} \mathrm{7.4)}$ and vortexed for $60 \mathrm{~s}$ to release cellular material into fluid. The swabs were then removed and the PBS suspensions were ready for DNA extraction. Nasal and tracheal aspirates were subjected to direct DNA extraction.

DNA extraction was performed using QIAamp DNA blood mini kit (QIAGEN), following the manufacturer's instructions. The DNA was kept at $-20^{\circ} \mathrm{C}$ until further testing. The primers used for the end-point PCR are listed in Table 1. The DNA was first screened for the presence of IS481 using BP1 and BP2 primers [19]. Amplification was performed using Biometra TPersonal version 2.0 (Biometra Gmbh, Goettingen, Germany) with the following parameters: predenaturation at $95^{\circ} \mathrm{C}$ for $5 \mathrm{~min}$, followed by 30 cycles of denaturation at $95^{\circ} \mathrm{C}$ for $1 \mathrm{~min}$, annealing at $57^{\circ} \mathrm{C}$ for $1 \mathrm{~min}$, extension at $72^{\circ} \mathrm{C}$ for $1 \mathrm{~min}$ with a final extension at $72^{\circ} \mathrm{C}$ for $5 \mathrm{~min}$. The expected end-point PCR product size for fragment of IS481 is $151 \mathrm{bp}$.

If the screening test was positive, the extracted DNA was then subjected to end-point PCR amplification of pertussis toxin (PT) promoter using BPTOX F and BPTOX R primers [19]. The parameters used were as follows: predenaturation at $95^{\circ} \mathrm{C}$ for $5 \mathrm{~min}$, followed by 30 cycles of denaturation at $95^{\circ} \mathrm{C}$ for $1 \mathrm{~min}$, annealing at $60^{\circ} \mathrm{C}$ for $1 \mathrm{~min}$, extension at $72^{\circ} \mathrm{C}$ at $1 \mathrm{~min}$ with a final extension at $72^{\circ} \mathrm{C}$ for $5 \mathrm{~min}$. The expected end-point PCR product size of fragment of PT promoter is 190 bp.

The internal control primers $\mathrm{Hg} 1$ and $\mathrm{Hg} 2$ were used in both screening and confirmatory test to target a region of
TABLE 1: Sequences of the primers.

\begin{tabular}{lc}
\hline Primer & \multicolumn{1}{c}{ Sequence } \\
\hline BP1 & $5^{\prime}$-GAT TCA ATA GGT TGT ATG CAT GGT T-3' \\
BP2 & $5^{\prime}$-TGG ACC ATT TCG AGT CGA CG-3 \\
BPTOX F & $5^{\prime}$-GCG CAT GCG TGC AGA TTC GTC-3' \\
BPTOX R & $5^{\prime}$-CCC TCT GCG TTT TGA TGG TGC C-3' \\
HG1 & $5^{\prime}$-CAA CTT CAT CCA CGT TCA CC-3' \\
HG2 & $5^{\prime}$-GAA GAG CCA AGG ACA GGT AC-3' \\
\hline
\end{tabular}

human hemoglobin gene as described by [20]. The expected end-point PCR product size for internal control is $268 \mathrm{bp}$.

The end-point PCR products were visualized by $1.5 \%$ agarose gel electrophoresis stained with RedSafe TM Nucleic Acid Staining Solution (iNtRON Biotechnology Inc., Sungnam, Kyungki-Do, Republic of Korea) and documented with a ChemiDoc XRS+ system (Bio-Rad, Hercules, CA, USA).

The end-point PCR result was considered positive if both target and internal control bands or target band alone was obtained. However, it was considered negative when the internal control band alone was observed. Cases were defined as positive if both screening and confirmatory tests were positive.

\section{Results}

From the 707 samples processed, 275 samples were positive for Bordetella pertussis. Four cases were detected by culture method alone, 6 were detected by both end-point PCR and culture methods, and another 265 were detected by endpoint PCR alone. Overall, 454 samples were positive in IS481 screening test and only 271 samples $(60 \%)$ were positive in PT promoter confirmatory test. For those negative in confirmatory test (183 samples), the cases were recognized as Bordetella spp.

Most of the positive cases were obtained from nasopharyngeal aspirates $(40.9 \%)$, followed by nasopharyngeal swab (35.6\%), pernasal swab (33.3\%), tracheal aspirate (28.6\%), and throat swab (14.3\%) and none from endotracheal tube swab (Table 2).

The majority of positive cases were from Kedah (42/275), Terengganu (39/275), and Selangor (35/275). The lowest number of pertussis cases was found in Kuala Lumpur with 2 cases only.

Positive cases were highest among patients aged $\leq 3$ months old (212/275) followed by patients with aged 4-12 months old (37/275). However, there were also 12 cases detected from individuals between 13 to 24 months old and 14 cases in individuals more than 24 months old (Table 3 ).

\section{Discussion}

The end-point PCR assay has been used to detect $B$. pertussis in the routine work [19]. It was shown to be rapid and highly sensitive compared to culture which is slow and has low sensitivity. Although culture has high specificity, it can be affected by several factors such as specimen transport condition, illness duration, and antibiotic treatment [21, 22]. 
TABLE 2: Number of positive cases which detected from different specimens.

\begin{tabular}{lcccc}
\hline \multirow{2}{*}{$\begin{array}{l}\text { Specimen type } \\
\text { Total number of specimens }\end{array}$} & Culture only & $\begin{array}{c}\text { Number of positive specimens } \\
\text { End-point PCR only }\end{array}$ & Culture and end-point PCR \\
\hline Nasopharyngeal aspirate & 521 & 3 & 207 & 3 \\
Nasopharyngeal swab & 149 & 0 & 50 & 3 \\
Tracheal aspirate & 7 & 0 & 2 & 0 \\
Throat swab & 14 & 1 & 5 & 0 \\
Pernasal swab & 15 & 0 & 0 & 0 \\
Endotracheal tube swab & 1 & 0 & 5 & 0 \\
\hline
\end{tabular}

TABLE 3: Age range (month) of positive pertussis cases.

\begin{tabular}{lcccc}
\hline \multirow{2}{*}{ Age (month) } & \multirow{2}{*}{ Total number of specimens } & \multicolumn{2}{c}{ Number of pertussis cases } \\
Culture and end- point PCR \\
\hline$<1$ & 37 & 0 & 13 & 0 \\
$1-3$ & 431 & 4 & 189 & 6 \\
$4-6$ & 105 & 0 & 20 & 0 \\
$7-9$ & 38 & 0 & 7 & 0 \\
$10-12$ & 32 & 0 & 10 & 0 \\
$13-15$ & 7 & 0 & 4 & 0 \\
$16-18$ & 9 & 0 & 3 & 0 \\
$19-21$ & 7 & 0 & 1 & 0 \\
$22-24$ & 8 & 0 & 4 & 0 \\
$>24$ & 33 & 0 & 14 & 0 \\
\hline
\end{tabular}

In this study, we screened the samples for the presence of IS481 and proceeded to the detection of pertussis toxin when IS481 screening was positive. The repetitive insertion sequence IS481 was shown to be present in $B$. pertussis with 200 copy numbers $[23,24]$. However, it was not specific enough as it is also present in $B$. holmesii and B. bronchiseptica [25]. The other major virulent determinant is pertussis toxin promoter region which is present as a single-copy gene. Single-target testing using IS481 may miss up to $20 \%$ of true positive cases [17]. Therefore, we used dual-target PCR assay targeting IS481 and pertussis toxin promoter region as practiced by other researchers to increase the sensitivity of the test $[19,26]$. The internal control was introduced into the assay to differentiate between false negative and true negative results [27].

There were four cases that were culture positive but undetectable by our end-point PCR assay. We believe this could be due to the inhibitory substances which may be present in the specimens as described by Douglas et al. [28]. Mattoo and Cherry [29] have suggested treating the specimens with mucolytic agent to remove the inhibitory substances prior to the end-point PCR.

There were several factors that could lead to the culture sensitivity in this study. Many of the samples were not received on the same day of specimen collection except from the states of Selangor, Kuala Lumpur, and Putrajaya, which are geographically near our laboratory. Besides, we found that some of the swabs were not transported in the proper transport media, namely, Regan-Lowe medium, as suggested by WHO [30]. Prior antibiotic treatment before collection of samples could also affect the growth of $B$. pertussis $[31,32]$. Most of the patients had been on antibiotic treatment before their samples were collected and this could contribute to the inability to recover viable bacteria by culture method.

There was no significant association between the types of samples collected and end-point PCR results $(P>0.05)$ (chisquare test by software SPSS 16). However, nasopharyngeal aspirate samples had the highest number of positive endpoint PCR results (40.3\%) compared to nasopharyngeal swab (35.6\%) and others (21.6\%). Douglas et al. [28] described that the low detection in the swab specimens was because of the insufficient cells found on the swabs. In contrast, Farrell et al. [23] obtained high percentage of end-point PCR positive from throat swab specimens in their study. The detection from throat swab in our study was low, that is, $0.4 \%$ and $10 \%$ from end-point PCR and culture, respectively. The small number of throat swab samples in this study could also contribute to the low number of positive results.

In our study, infant aged $\leq 3$ months old was the highest group to be infected by $B$. pertussis. This result was expected because they have not been fully vaccinated. The proportion of those in the age group $\leq 3$ months old (45.3\%) with positive result was significantly higher than that in the age group $>3$ months old $(26.4 \%)(P<0.001)$ (chi-square test by software SPSS 16). This could be due to the direct transmission from their parents, relatives, or guardians who may be the reservoir for the bacteria. This idea was supported by Kenneth et al. [33] who stated that immunity against pertussis vaccination will wane after 10-year-vaccination, and the transmission 
rate to infant by household caretaker ranged between $30-$ $40 \%$. Hence, booster immunizations of adolescents in 10-19 years old are strongly suggested to reduce disease burden, healthcare setting cost and increase work productivity [33, 34].

\section{Conclusion}

In conclusion, our study showed that more pertussis cases were detected by end-point PCR compared with culture method. Most of the positive samples were from nasopharyngeal aspirates. However, there is no significant association between the type of specimens and the end-point PCR results. Most of the cases involved $\leq 3$ months old patients who had not completed the scheduled vaccinations. Education and awareness are necessary to prevent the disease becoming widespread.

\section{Conflict of Interests}

The authors have no conflict of interests to declare.

\section{Acknowledgment}

The authors thank the Director General of Health, Ministry of Health Malaysia for permission to publish this paper.

\section{References}

[1] World Health Organization, "Pertussis vaccines- WHO position paper," Weekly Epidemiology Record, vol. 85, no. 40, pp. 385-400, 2010.

[2] Centers for Disease Control and Prevention, "Pertussis. Epidemiology and prevention of vaccine- preventable disease," in Vaccines and Immunizations, vol. 12, pp. 215-232, 12th edition, 2012.

[3] A. M. Wendelboe, A. Van Rie, S. Salmaso, and J. A. Englund, "Duration of immunity against pertussis after natural infection or vaccination," Pediatric Infectious Disease Journal, vol. 24, no. 5, pp. S58-S61, 2005.

[4] EUVAC-NET. EUVAC-NET pertussis surveillance report, 2003-2007, 2009, http://www.euvac.net/graphics/euvac/pdf/ pertussis2.pdf.

[5] Centers for Disease Control and Prevention, "Summary of notifiable diseases: United States, 2009," Morbidity and Mortality Weekly Report, vol. 58, no. 53, pp. 1-100, 2011.

[6] Ministry of Health Malaysia, "Pertussis," 2012, http://www.myhealth.gov.my/v2/index.php/my/pertussis.

[7] Ministry of Health of Malaysia, "Childhood Immunisationhealth technology assessment," 2002, http://www.moh.gov.my/ attachments/745.

[8] Ministry of Health of Malaysia and Academy of Medicine of Malaysia, Clinical Practice Guidelines-Childhood Immunisation, 2004, http://www.moh.gov.my/attachments/3934.

[9] Ministry of Health of Malaysia, Case Definitions for Infectious Diseases in Malaysia, 2nd edition, 2006, http://jknsarawak.moh .gov.my/en/uploads/case_definitions_for_infectious_diseases_in_ malaysia_2nd_edition_jan_2006.pdf.

[10] Ministry of Health of Malaysia, “Annual report 2010," 2012, http://www.moh.gov.my/v/duk.
[11] Ministry of Health of Malaysia, "Case investigation and outbreak management for healthcare personnel: pertussis," 2010, http://jknkelantan.moh.gov.my/v3/uploads/PDdownloads/guidelines_on_pertussis_case_and_outoutbr_management[1].pdf.

[12] World Health Organization, "Pertussis vaccines- WHO position paper," Weekly Epidemiological Record, vol. 80, no. 4, pp. 29-40, 2005.

[13] E. Rothstein and K. Edwards, "Health burden of pertussis in adolescents and adults," Pediatric Infectious Disease Journal, vol. 24, no. 5, pp. S44-S47, 2005.

[14] Centers for Disease Control and Prevention, "Pertussis (whooping cough)-complications," 2013, www.cdc.gov/pertussis/about/complications.html.

[15] F. Zepp, U. Heininger, J. Mertsola et al., "Rationale for pertussis booster vaccination throughout life in Europe," The Lancet Infectious Diseases, vol. 11, no. 7, pp. 557-570, 2011.

[16] L. Knorr, J. D. Fox, P. A. G. Tilley, and J. Ahmed-Bentley, "Evaluation of real-time PCR for diagnosis of Bordetella pertussis infection," BMC Infectious Diseases, vol. 6, article 62, 2006.

[17] X. Qin, E. Galanakis, E. T. Martin, and J. A. Englund, "Multitarget PCR for diagnosis of pertussis and its clinical implications," Journal of Clinical Microbiology, vol. 45, no. 2, pp. 506-511, 2007.

[18] M. Riffelmann, C. H. W. Von König, V. Caro, and N. Guiso, "Nucleic acid amplification tests for diagnosis of Bordetella infections," Journal of Clinical Microbiology, vol. 43, no. 10, pp. 4925-4929, 2005.

[19] D. M. Dragsted, B. Dohn, J. Madsen, and J. S. Jensen, "Comparison of culture and PCR for detection of Bordetella pertussis and Bordetella parapertussis under routine laboratory conditions," Journal of Medical Microbiology, vol. 53, no. 8, pp. 749-754, 2004.

[20] J. R. Lingappa, W. Lawrence, S. West-Keefe, R. Gautom, and B. T. Cookson, "Diagnosis of community-acquired pertussis infection: comparison of both culture and fluorescent-antibody assays with PCR detection using electrophoresis or dot blot hybridization," Journal of Clinical Microbiology, vol. 40, no. 8, pp. 2908-2912, 2002.

[21] H. O. Hallander, "Microbiological and serological diagnosis of pertussis," Clinical Infectious Diseases, vol. 28, no. 6, pp. S99S106, 1999.

[22] R. M. Wadowsky, R. H. Michaels, T. Libert, L. A. Kingsley, and G. D. Ehrlich, "Multiplex PCR-based assay for detection of Bordetella pertussis in nasopharyngeal swab specimens," Journal of Clinical Microbiology, vol. 34, no. 11, pp. 2645-2649, 1996.

[23] D. J. Farrell, G. Daggard, and T. K. S. Mukkur, "Nested duplex PCR to detect Bordetella pertussis and Bordetella parapertussis and its application in diagnosis of pertussis in nonmetropolitan southeast Queensland, Australia," Journal of Clinical Microbiology, vol. 37, no. 3, pp. 606-610, 1999.

[24] J. Parkhill, M. Sebaihia, A. Preston et al., "Comparative analysis of the genome sequences of bordetella pertussis, Bordetella parapertussis and Bordetella bronchiseptica," Nature Genetics, vol. 35, no. 1, pp. 32-40, 2003.

[25] A. Tizolova, N. Guiso, and S. Guillot, "Insertion sequences shared by Bordetella species and implications for the biological diagnosis of pertussis syndrome," European Journal of Clinical Microbiology \& Infectious Diseases, vol. 32, no. 1, pp. 89-96, 2013.

[26] K. M. Tatti, K. H. Wu, M. L. Tondella et al., "Development and evaluation of dual-target real-time polymerase chain reaction assays to detect Bordetella spp," Diagnostic Microbiology and Infectious Disease, vol. 61, no. 3, pp. 264-272, 2008. 
[27] P. Mastrantonio, P. Stefanelli, and M. Giuliano, "Polymerase chain reaction for the detection of Bordetella pertussis in clinical nasopharyngeal aspirates," Journal of Medical Microbiology, vol. 44, no. 4, pp. 261-266, 1996.

[28] E. Douglas, J. G. Coote, R. Parton, and W. McPheat, "Identification of Bordetella pertussis in nasopharyngeal swabs by PCR amplification of a region of the adenylate cyclase gene," Journal of Medical Microbiology, vol. 38, no. 2, pp. 140-144, 1993.

[29] S. Mattoo and J. D. Cherry, "Molecular pathogenesis, epidemiology, and clinical manifestations of respiratory infections due to Bordetella pertussis and other Bordetella subspecies," Clinical Microbiology Reviews, vol. 18, no. 2, pp. 326-382, 2005.

[30] World Health Organization, Laboratory Manual For the Diagnosis of the Whooping Cough Caused By Bordetella Pertussis/ Bordetella Parapertussis, chapter 3, 2007.

[31] A. Faulkner, T. Skoff, S. Martin et al., "Pertussis. Manual for the Surveillance of Vaccine-Preventable Diseases," in Manual For the Surveillance of VaccIne-Preventable Diseases, 5th edition, 2011.

[32] L. Gustafsson, H. O. Hallander, P. Olin, E. Reizenstein, and J. Storsaeter, "A controlled trial of a two-component acellular, a five-component acellular, and a whole-cell pertussis vaccine," The New England Journal of Medicine, vol. 334, no. 6, pp. 349355, 1996.

[33] W. P. Kenneth, W. H. Joel, F. B. Marc, and I. W. Joel, "Evaluation of strategies for use of acellular pertussis vaccine in adolescents and adults: a cost-benefit analysis," Clinical Infectious Diseases, vol. 39, no. 1, pp. 20-28, 2004.

[34] J. I. Ward, J. D. Cherry, S. J. Chang et al., "Efficacy of an acellular pertussis vaccine among adolescents and adults," The New England Journal of Medicine, vol. 353, no. 15, pp. 1555-1563, 2005. 

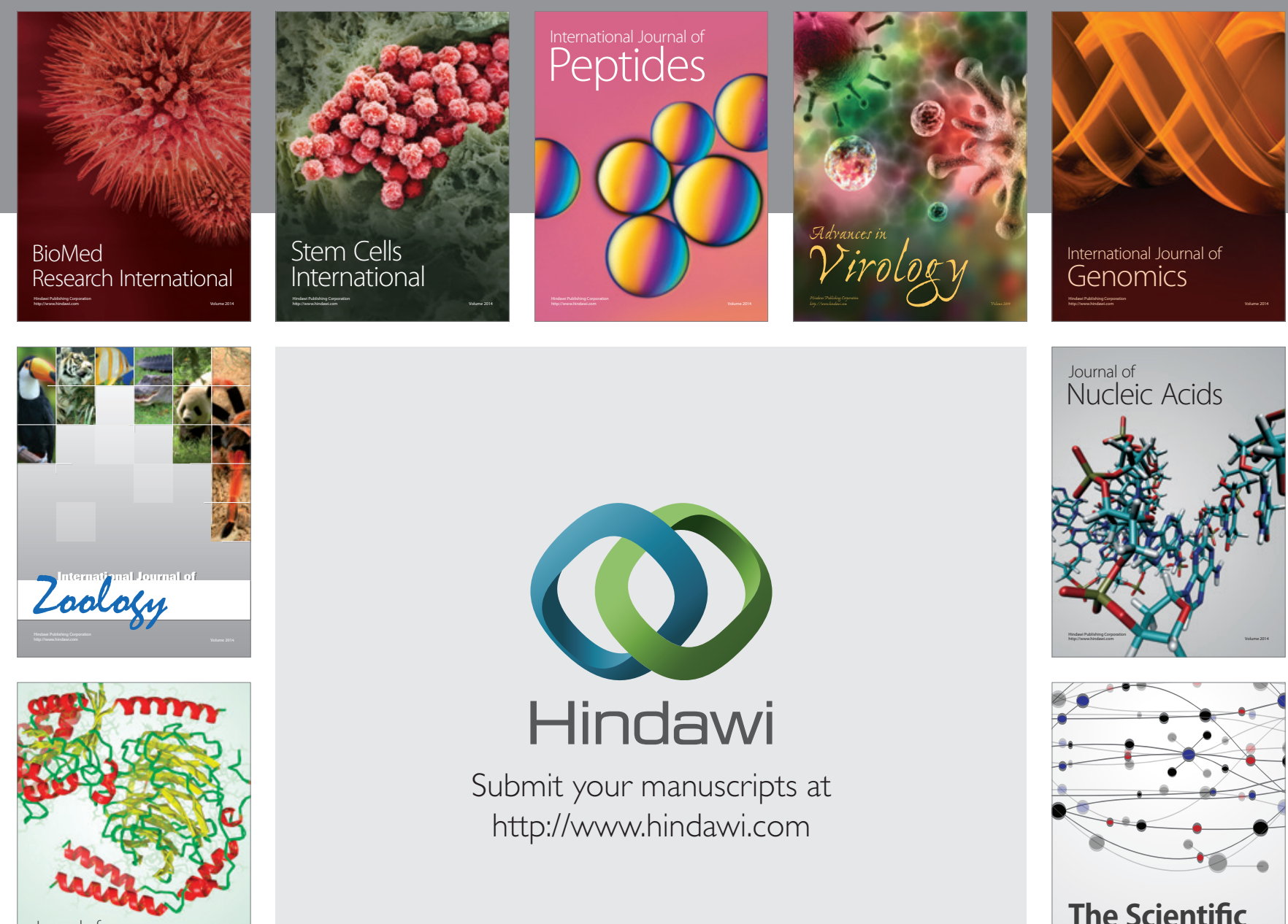

Submit your manuscripts at

http://www.hindawi.com

Journal of
Signal Transduction
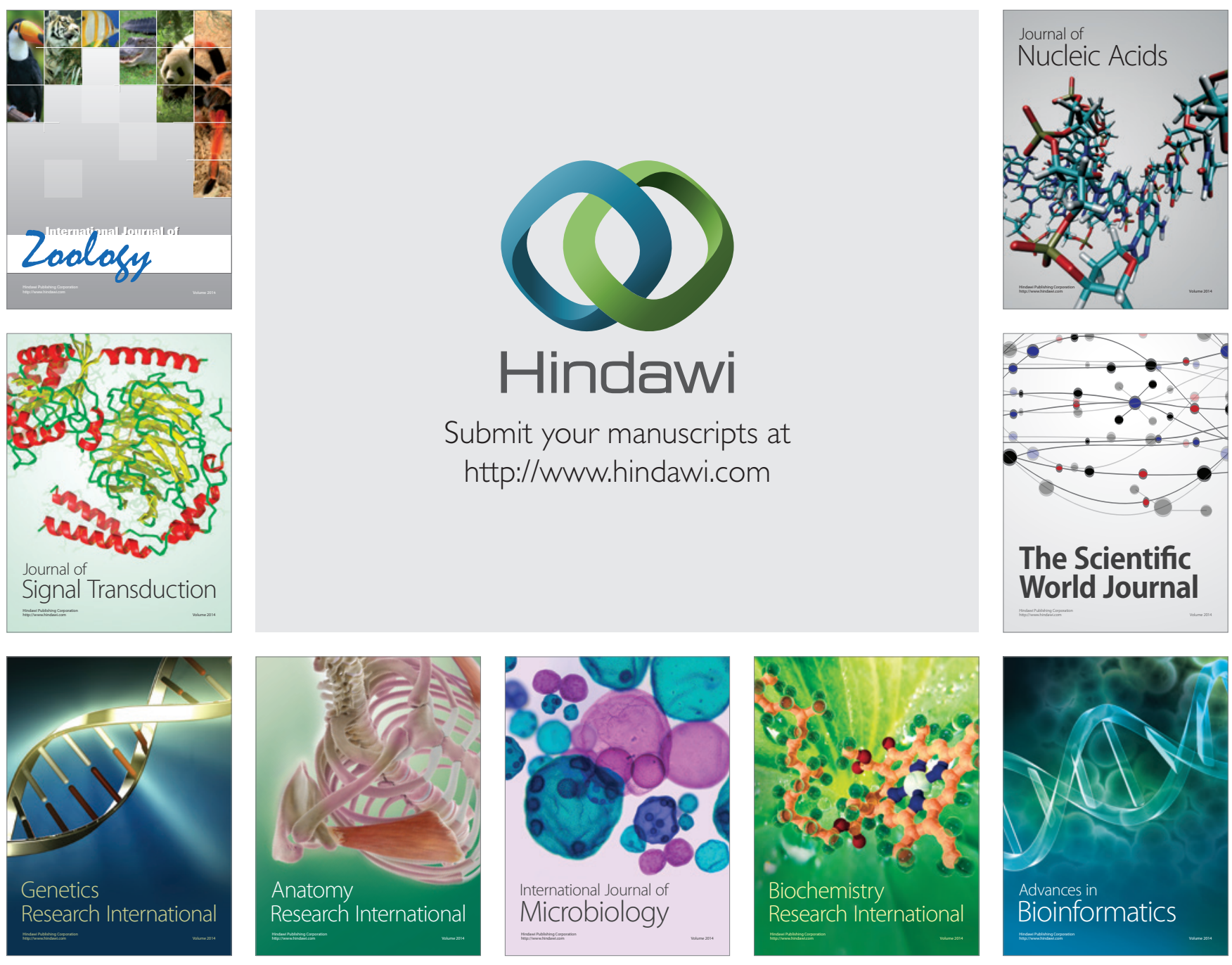

The Scientific World Journal
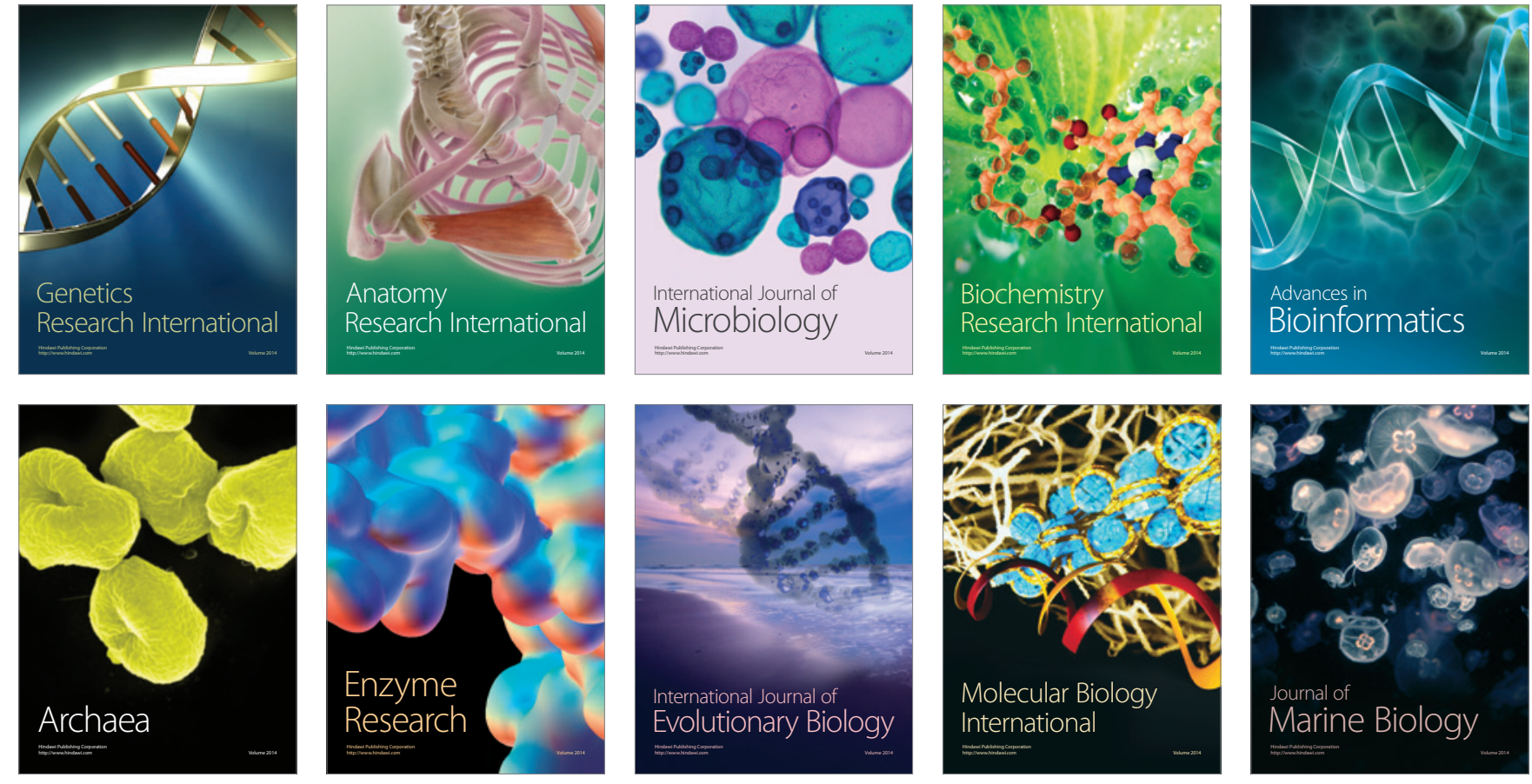